\title{
Evaluation of pheniramine maleate and zofenopril in reducing renal damage induced by unilateral ureter obstruction. An experimental study
}

\author{
Ercan Yuvanc ${ }^{1}$, Devrim Tuglu ${ }^{1}$, Tunc Ozan² ${ }^{2}$ Ucler Kisa ${ }^{3}$, Mahi Balci ${ }^{4}$, Ertan Batislam ${ }^{1}$, Erdal Yilmaz ${ }^{1}$
}

\begin{abstract}
${ }^{1}$ Department of Urology, Kirikkale University School of Medicine, Kirikkale, Turkey 2Department of Urology, Firat University School of Medicine, Elazig, Turkey

${ }^{3}$ Department of Biochemistry, Kirikkale University School of Medicine, Kirikkale, Turkey ${ }^{4}$ Department of Pathology, Kirikkale University School of Medicine, Kirikkale, Turkey
\end{abstract}

Submitted: 28 December 2017; Accepted: 14 March 2018;

Online publication: 4 October 2019

Arch Med Sci 2021; 17 (3): 812-817

DOI: https://doi.org/10.5114/aoms.2019.88320

Copyright $\odot 2019$ Termedia \& Banach

\section{Abstract}

Introduction: Obstruction of the ureter may occur due to congenital, iatrogenic or other reasons. This can cause hydronephrosis in the early stage and can lead to cellular inflammation, necrosis and atrophy in the kidney tissue. The aim of this paper is to evaluate the protective effect of pheniramine maleate (PM) and zofenopril on renal damage caused by hydronephrosis due to unilateral partial ureter obstruction.

Material and methods: Twenty-four female Sprague Dawley rats were divided into 4 groups. Group 1: sham group, group 2: partial unilateral ureteral obstruction (PUUO) group, group 3: PUUO + PM group, group 4: PUUO + zofenopril group. Paraoxonase (PON), total antioxidant status (TAS) and total oxidant status (TOS) of tissue and blood samples were measured and calculated. Tissue samples were evaluated histopathologically.

Results: An increase in tissue TAS and a decrease in tissue TOS and OSI levels were detected in groups 3 and 4 compared to group 2 (both: $p<0.01$ ). Tissue PON levels showed an increase in groups 3 and 4 compared to groups 1 and 2 (both: $p<0.01$ ). Histopathological evaluation showed a decrease in interstitial inflammation and congestion in groups 3 and 4 compared to the control group ( $p<0.001)$. The decrease was observed to be more significant in group 4 compared to group 3 ( $p<0.01)$.

Conclusions: In our experimental study, we observed that PM and zofenopril reduce the oxidation and tissue damage caused by unilateral partial obstruction.

Key words: kidney, partial unilateral ureter obstruction, hydronephrosis, pheniramine maleate, zofenopril, total antioxidant capacity, total oxidant status, oxidative stress index, paraoxonase.

\section{Introduction}

Obstruction of the ureter may occur due to congenital, iatrogenic or other reasons. This can cause hydronephrosis in the early stage and can lead to cellular inflammation, necrosis and atrophy in the kidney tissue [1]. Treatment of upper urinary tract obstructions aims to resolve the obstruction and protect and/or to regain the functional reserve of the kidneys. But it is obvious that long lasting obstructions will cause a decrease in the functional reserve of the kidneys. Studies have shown that reactive oxygen species (ROS) are responsible for the ischemia-reperfusion (I/R) damage.
Corresponding author: Assoc. Prof. Devrim Tuglu Department of Urology Kirikkale University School of Medicine 71100 Kirikkale, Turkey Phone: +0903183335000 E-mail: devrimtuglu@gmail.com 
ROS disturb structural elements of the tissue and may cause damage. Several studies have reported about (I/R) damage in various tissue samples and that this tissue damage may be decreased with antioxidant therapy [2, 3].

Zofenopril is a proline amino acid derived lipophilic angiotensin converting enzyme (ACE) inhibitor with a long lasting tissue penetration feature. Experimental studies have shown that it reduces cardiac and renal I/R damage with its antioxidant feature and has a supportive cardiovascular effect in myocardial infarction patients $[4,5]$. Pheniramine maleate (PM) is an alkylamine derived $\mathrm{H}_{1}$ receptor antagonist and is believed to prevent the formation and/or secretion of ROS by adhesion on cell membrane due to its lipophilic feature [6]. In vitro studies have shown that PM achieves this effect through activated neutrophils. It is thought that this antioxidant effect may be of benefit by reducing the tissue damage [7].

The aim of our study was to evaluate the antioxidant effect of PM and zofenopril on the oxidative stress and histopathological changes by partial unilateral ureteral obstruction (PUUO).

\section{Material and methods}

Twenty-four 3-4 months old female SpragueDawley rats weighing between 150 and $250 \mathrm{~g}$ were used. All procedures on the animals were performed according to the conditions of the 1986 Strasbourg Universal Declaration on Animal Welfare in the Medical Scientific Experimental Research and Practice Center (MSERPC) of Ankara Education and Research Hospital with the approval of the local ethic committee (Protocol Number: 06.03.2014/274) under the control of veterinary physicians. The animals were sheltered in standard rat cages, 6 per cage, under MSERPC controlled conditions and were fed with pellet feed for rodents and tap water. Removal of animal excretions, food and water supply and cleaning of the cages were provided by experienced staff and the veterinary physician of the center.

\section{Surgical preparation of partial unilateral ureteral obstruction}

After induction of general anesthesia with xylazine (5-10 mg/kg; IM) (Rompun, Bayer-Istanbul) and ketamine hydrochloride (50-70 mg/kg; IM) and antibiotic prophylaxis with ampicillin $(100 \mathrm{mg} / \mathrm{kg}$; IM) the operation site was disinfected with $10 \%$ povidone iodine solution. A $2 \mathrm{~cm}$ midline longitudinal abdominal incision was made that permitted access to the right kidney, ureter, and psoas muscle. Partial UUO was accomplished by enveloping the lower right ureter in the psoas muscle with a single suture of 2-0 silk transfixing the muscle laterally and medially creating a muscular tunnel through which the ureteral segment was gently compressed. To produce a unilateral partial obstruction the psoas-implanting technique described in 1962 by Ulm and Josephson was adapted $[8,9]$. In sham operated rats, the ureter was exposed but not obstructed. The incision was closed according to the anatomic layers and a warm wet dressing was put on the incision wound.

Rats were administered meperidine $\mathrm{HCl}$ 5-10 mg/ kg i.p. for postoperative analgesia and they were fed after recovery from anesthesia. On the $15^{\text {th }}$ postoperative day the abdominal incisions were opened, the ligated ureter was excised including the renal pelvis, simple nephrectomy was performed and blood samples were taken from the vena cava inferior [10]. Specimens were isolated in phenol and stored at $+4^{\circ} \mathrm{C}$ for histopathological examination.

\section{Study groups}

Rats were divided into 4 groups:

- Group 1 (sham), consisting of 6 rats. The surgical procedure described above was performed without the ureter obstruction step and right nephrectomy through the same incision was performed immediately after closing it.

- Group 2 (control group), consisting of 6 rats. The surgical procedure mentioned above was performed. The rats did not receive any medication after surgery.

- Group 3 (PUUO + pheniramine maleate group), consisting of 6 rats. Rats with partial unilateral ureteral obstruction were given PM 10 mg/kg/ day i.p. for 14 days.

- Group 4 (PUUO + zofenopril group), consisting of 6 rats. Rats with partial unilateral ureteral obstruction were given zofenopril $10 \mathrm{mg} / \mathrm{kg} /$ day i.p. for 14 days.

On the $15^{\text {th }}$ day after the first operation the right nephrectomy procedure was performed in groups 2, 3, 4 through the abdominal incision. Tissue and blood samples were collected and biochemically evaluated in terms of total antioxidant status (TAS), total oxidant status (TOS), oxidative stress index (OSI) and paraoxonase (PON) parameters and histopathologically according to cellular morphology.

\section{Histopathologic, immunohistochemical and biochemical evaluation}

\section{Hematoxylin-eosin staining}

Tissue samples were fixed in 10\% neutral buffered formalin for light microscopic examination. After the routine tissue preparation process, $5 \mu \mathrm{m}$ sections were taken with a rotary microtome (RM 2135, Leica). Slides are placed into hematoxylin (01562E, Surgipath, Bretton, Peterborough, Cam- 
bridgeshire) and eosin (01602E, Surgipath, Bretton, Peterborough, Cambridgeshire). After routine tissue preparation the slides were then dried in air processed with xylene for gaining transparence for 30 min and covered with Entellan (UN 1866, Merck, Darmstadt, Germany) [11]. All sections of kidney samples were examined for tubular necrosis. Briefly, a minimum of 50 proximal tubules associated with 50 glomeruli were examined for each slide and an average score was obtained. Severity of lesion was graded from 0 to 3 according to the percentage of tubular involvement. Slides were examined and assigned for severity of changes using scores on a scale in which 0 denotes no change; grade 1 - changes affecting < 25\% tubular damage (mild); grade 2 changes affecting $25-50 \%$ of tubules (moderate); grade 3 - changes affecting > 50\% of tubules (severe). A semiquantitative evaluation of renal tissues was accomplished by scoring the degree of severity according to previously published criteria [12]. Histopathological analysis was performed by the same blinded pathologist at Kirikkale University Medical Faculty Pathology Department.

\section{Total antioxidant status (TAS)}

TAS kit was used for the measurement of total antioxidant status. TAS level was determined using the method developed by Erel. The principle of the method was based on the chemical reduction of the of the blue-green colored ABTS radical into the colorless ABTS form by the antioxidants. For the measurement a spectrophotometer (Shimadzu UV 1700A) was used at $25^{\circ} \mathrm{C}$. Serum TAS levels were calculated in mmol Trolox equivalent// with the formula TAS $=([\Delta$ Abs standard 1$]-[\Delta$ Abs sample $]) /$ ([ $\Delta$ Abs standard 1] $-[\Delta$ Abs standard 2]) [13].

\section{Total oxidant status (TOS)}

TOS levels were determined using a TOS kit which operates using a novel automated and colorimetric measurement method as previously described by Erel. The principle of the meth- od is based on the oxidation of ferrous ion-chelate complex to ferric ions by the oxidants in the sample. The TAS measurement by the mentioned spectrophotometer was used and serum TOS levels were calculated with the formula TOS $=([\Delta \mathrm{Abs}$ serum $] /[\Delta$ Abs standard $]) \times 20$ in $\mu \mathrm{mol} \mathrm{H}_{2} \mathrm{O}_{2}$ equivalent/l [14].

\section{Calculation of oxidative stress index (OSI)}

The TOS : TAS ratio was used as the OSI. To perform the calculation, the unit of TAS, mmol Trolox equivalent/l, was converted to mmol Trolox equivalent/l, and OSI was calculated as follows: OSI = [TOS, mmol $\mathrm{H}_{2} \mathrm{O}_{2}$ equivalent/l]/[TAS, mmol Trolox equivalent/l] $\times 100$ [14].

\section{Paraoxonase (PON)}

PON activity was measured with a commercial experimental kit (Relassay, Gaziantep, Turkey). PON measurement may be performed by presence or absence of $\mathrm{NaCl}$ and $\mathrm{M}^{-1} \mathrm{~cm}^{-1}$ enzyme activity was calculated by using the 18290 molar absorption index [15].

\section{Statistical analysis}

The statistical evaluation of the obtained data was performed with SPSS 21 (IBM Corp., Armonk, NY, USA) and SAS version 9.4 (SAS Institute, Inc., Cary, NC, USA) by an independent, dedicated biostatistician uninvolved in the study and blinded to treatment assignment, and the results are expressed as the median and interquartile range. Differences between groups were analyzed with ANOVA test (with post hoc Tukey test for unequal groups) and statistical significance was determined as $p<0.05$.

\section{Results}

\section{Biochemical findings and results}

The mean values of TAS levels were statistically significantly higher in groups 3 and $4(0.91 \pm 0.01$

Table I. Biochemical results

\begin{tabular}{|c|c|c|c|c|c|}
\hline Parameter & $\begin{array}{l}\text { Group } 1 \text { - Sham } \\
\qquad(n=6)\end{array}$ & $\begin{array}{l}\text { Group } 2- \\
\text { PUUO (control) } \\
(n=6)\end{array}$ & $\begin{array}{l}\text { Group } 3- \\
\text { PUUO + PM } \\
(n=6)\end{array}$ & $\begin{array}{c}\text { Group } 4- \\
\text { PUUO + zofenopril } \\
(n=6)\end{array}$ & $\begin{array}{l}P \text {-value } \\
\text { ANOVA }\end{array}$ \\
\hline $\begin{array}{l}\text { TAS [nmol Trolox equiv. } \\
\text { per mg protein] }\end{array}$ & $0.68 \pm 0.08$ & $0.82 \pm 0.04$ & $0.91 \pm 0.01$ & $0.98 \pm 0.03$ & $<0.001$ \\
\hline $\begin{array}{l}\text { TOS [nmol } \mathrm{H}_{2} \mathrm{O}_{2} \text { equiv. } \\
\text { per mg protein] }\end{array}$ & $19.18 \pm 0.52$ & $25.33 \pm 3.89$ & $15.28 \pm 1.24$ & $13.82 \pm 2.51$ & $<0.001$ \\
\hline OSI [arbitrary unit] & $28.82 \pm 4.26$ & $30.97 \pm 3.97$ & $17.22 \pm 1.61$ & $14.17 \pm 3.22$ & $<0.001$ \\
\hline $\mathrm{PON}[\mathrm{mUl} / \mathrm{ml}]$ & $42.8 \pm 1.40$ & $33.2 \pm 2.50$ & $56.6 \pm 2.30$ & $72.3 \pm 1.90$ & $<0.001$ \\
\hline
\end{tabular}

Results are presented as mean \pm standard deviation or median (interquartile range). PUUO - partial unilateral ureteral obstruction, PM - pheniramine maleate, OSI - oxidative stress index, TAS - total antioxidant status, TOS - total oxidant status, PON - paraoxonase. 
mmol Trolox equivalent/l and $0.98 \pm 0.03 \mathrm{mmol}$ Trolox equivalent/l) compared to groups 1 and group 2 (0.68 $\pm 0.08 \mathrm{mmol}$ Trolox equivalent/l and $0.82 \pm 0.04 \mathrm{mmol}$ Trolox equivalent/l) respectively $(p<0.001)$ (Table I). There was a statistically significant difference in the TAS values between groups 3 and 4 in favor of group 4 $(p<0.001)$. Comparison of TOS levels revealed a statistically significantly lower level in group 4 (13.82 $\pm 2.51 \mu \mathrm{mol} \mathrm{H}_{2} \mathrm{O}_{2}$ equivalent/l) compared to group 1 $\left(19.18 \pm 0.52 \mu \mathrm{mol} \mathrm{H}_{2} \mathrm{O}_{2}\right.$ equivalent/l) $(p<0.001)$ and a lower level in groups 3 and group 4 (15.28 \pm 1.24 and $13.82 \pm 2.51 \mu \mathrm{mol} \mathrm{H}_{2} \mathrm{O}_{2}$ equivalent/l) respectively compared to group $2(25.33 \pm 3.89$ $\mu \mathrm{mol} \mathrm{H}_{2} \mathrm{O}_{2}$ equivalent/l) $(p<0.001)$. By the results of the parameter OSI a lower level was observed in groups 3 and $4(17.22 \pm 1.61 \mathrm{AU}$ and $14.17 \pm 3.22 \mathrm{AU})$ respectively compared to groups 1 and 2 (28.82 $\pm 4.26 \mathrm{AU}$ and $30.97 \pm 3.97 \mathrm{AU})$ respectively $(p<0.001)$ (Table I). There was a statistically significantly difference in the OSI values between groups 3 and 4 in favor of group $4(p<0.001)$.

Serum PON levels revealed a statistically significantly higher level in groups 3 and 4 (56.6 $\pm 2.3 \mathrm{mUl} / \mathrm{ml}$ and $72.3 \pm 1.9 \mathrm{mUl} / \mathrm{ml}$ ) respectively compared to groups 1 and $2(42.8 \pm 1.4 \mathrm{mUl} / \mathrm{ml}$ and $33.2 \pm 2.5 \mathrm{mUl} / \mathrm{ml})$ respectively $(p<0.001)$. Com- parison of group 4 with group 3 revealed a statistically significant difference in favor of group 4 $(p<0.001)$.

\section{Histopathologic findings and results}

In the histopathologic evaluation of the study groups, glomerular atrophy, tubular degeneration, interstitial inflammation and congestion were observed less often in PM and in the zofenopril group compared to the control group (Figure 1). Scoring was done in the manner described by Ozbek et al. [12]. This decrease was more significant in the zofenopril group (Table II).

\section{Discussion}

Upper urinary tract obstructions (UUTO) can cause kidney loss. The duration and the level of the obstruction determine the treatment option. The first aim of the treatment is to resolve the obstruction, protect and/or partially regain the renal function. In long lasting severe obstruction the functional reserve of the kidney will decrease and result in total renal failure and nephrectomy. In recent literature there are many studies describing the ischemia/reperfusion damage in several tis-
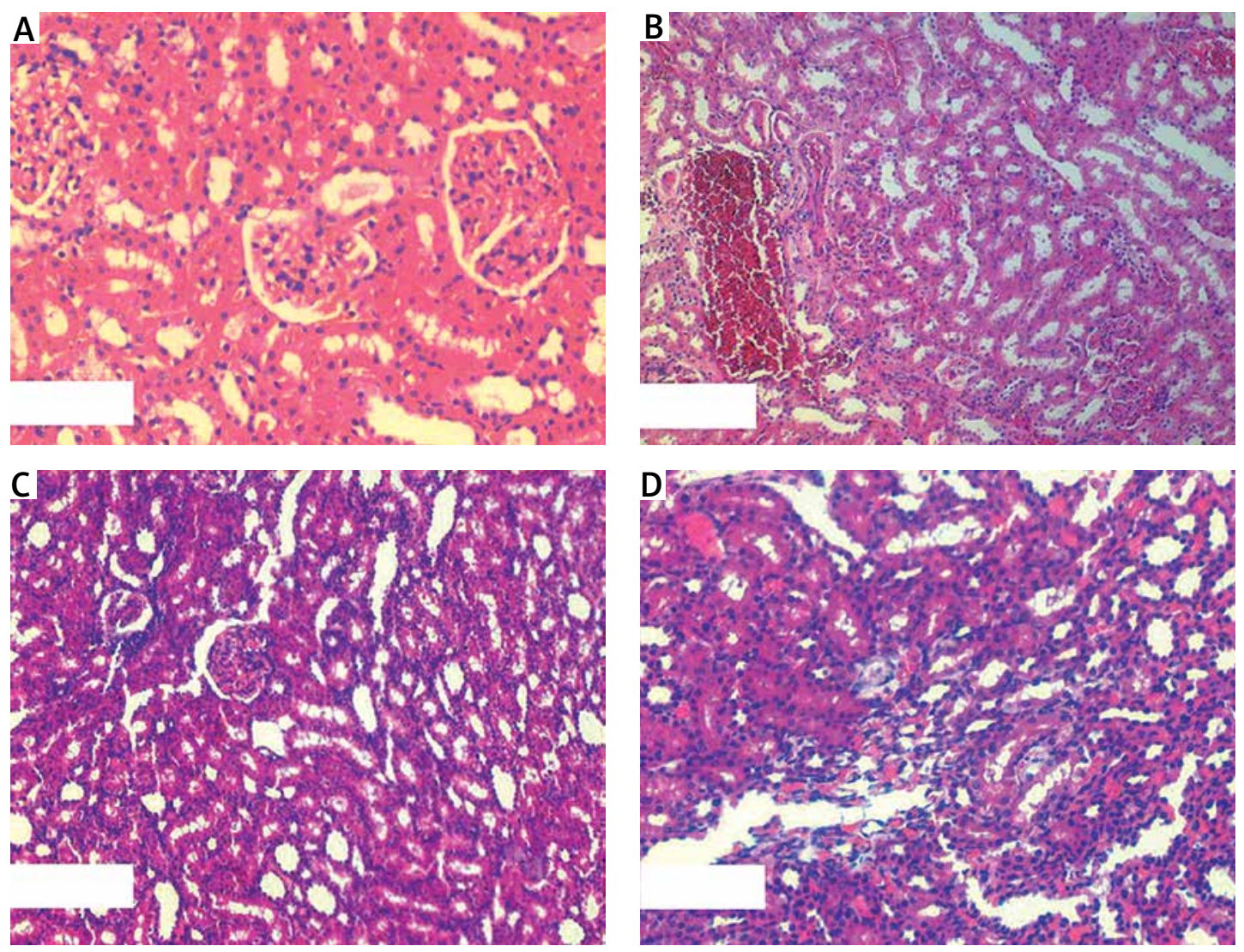

Figure 1. A - Control group: normal kidney tissue. B - PUUO group: kidney tissue specimen of PUUO group. C - Kidney tissue specimen of pheniramine maleate group. $\mathbf{D}$ - Kidney tissue specimen of zofenopril group 
Table II. Histopathologic results (histopathologic evaluation scoring)

\begin{tabular}{|lcccc|}
\hline Parameter & $\begin{array}{c}\text { Group 1 } \\
\text { Sham }\end{array}$ & $\begin{array}{c}\text { Group 2 } \\
\text { PUUO (control) }\end{array}$ & $\begin{array}{c}\text { Group 3 - } \\
\text { PUUO + PM }\end{array}$ & $\begin{array}{c}\text { Group 4 - } \\
\text { PUUO + zofenopril }\end{array}$ \\
\hline Interstitial inflammation & - & +++ & ++ & + \\
\hline Tubular and glomerular degeneration & - & ++ & ++ & + \\
\hline Tubular dilatation & - & ++ & ++ & + \\
\hline
\end{tabular}

PUUO - partial unilateral ureteral obstruction, $P M$ - pheniramine maleate.

sues and stating that antioxidant treatment may reduce this condition $[16,17]$.

As the oxidative and antioxidative system is a complex formation, it may be misleading to measure and evaluate it only with one biomarker. We aimed to analyze different parameters at the same time in order to evaluate renal damage in the early stage in our study. The results indicating a protective effect in various organs in the former studies on zofenopril and PM encouraged us to think that they may have a renal protective effect by hydronephrosis due to ureter obstruction, which is very common in urological practice. Nosalova and Bayrak demonstrated the I/R damage preventive effect of pheniramine on the gastrointestinal and renal system respectively $[7,18]$. Mak et al. detected that zofenopril has a protective effect against lipid peroxidation caused by the free radicals on endothelial cells [19]. Altunoluk et al. observed its protective effect against I/R damage by testis torsion [20].

Zofenopril is an antihypertensive drug and because of its common use by patients with heart diseases without any major side effects and its demonstrated beneficial effect in prior studies on experimental I/R on testis and heart, it may be of clinical use in patients with hydronephrosis due to ureter obstruction in order to protect renal function. Garrido et al. found that increased angiotensin-II levels enhance oxidative stress and Cacciatore et al. stated that ACE inhibitor treatment reduced oxidative stress [21, 22].

In our study PM and zofenopril biochemically decreased TOS and OSI. By comparison of these two drug groups with the control group it was revealed that zofenopril has a more potent effect than PM in the decline of the oxidative parameters (Table I). Histopathologic and immunohistochemical analyses revealed that PM and zofenopril decreased interstitial inflammation and congestion and this effect was observed as more significant in the zofenopril group (Table II). Also PON level, which is another indicator for antioxidant status, is observed to have decreased in the PM and zofenopril group (Table I).

It is certain that hydronephrosis will result in renal function loss. In this aspect, the time period under obstruction is of critical importance. Antioxidant agents may be useful in order to protect kidney function and reserves until the extinction of the obstruction and after [23-25]. Planning of future studies including renal function tests may bring addition of antioxidants into first line treatment options in order to protect the functions of the hydronephrotic kidneys.

The present study has some limitations. This is an experimental study using a relatively small number of animals from one strain, so the results may be limited to this species. It is not certain if the same results would be seen in different species, or in different models of kidney disease. This study may not represent much of the longer metabolic conditions that are exposed to pathology for a relatively short period of time. We believe that further experimental and clinical studies are needed for the mentioned clinical use of these two drugs.

In conclusion, the data from our study have shown that PM and zofenopril have antioxidant features by increasing TAS and decreasing TOS and OSI and PON levels, thus demonstrating upregulation as a systemic response in order to increase the TAS level. Histopathological examination revealed a more potent antiinflammatory effect in the zofenopril administered group. In the light of these results we consider that PM and zofenopril may have antioxidant and damage reducing effects by hydronephrosis due to partial ureteral obstruction.

\section{Conflict of interest}

The authors declare no conflict of interest.

\section{References}

1. Ucero AC, Gonçalves S, Benito-Martin A, et al. Obstructive renal injury: from fluid mechanics to molecular cell biology. Open Access J Urol 2010; 22: 41-55.

2. Özgür BC, Telli O, Yuceturk CN, et al. The effect of sildenafil and udenafil on testicular damage following ischemia-reperfusion injury in rats. J Urol 2014; 192: 1272-7.

3. Fadel FI, Elshamaa MF, Elghoroury EA, et al. Usefulness of serum procalcitonin as a diagnostic biomarker of infection in children with chronic kidney disease. Arch Med Sci Atheroscler Dis 2016; 5: e23-e31.

4. Yasar A, Erdemir F, Parlaktas BS, et al. The effect of carvedilol on serum and tissue oxidative stress parameters in partial ureteral obstruction induced rat model. Kaohsiung J Med Sci 2013; 29: 19-25.

5. Altunoluk B, Soylemez H, Oguz F, Turkmen E, Fadillioglu E. An angiotensin-converting enzyme inhibitor, zofenopril, 
prevents renal ischemia/reperfusion injury in rats. Ann Clin Lab Sci 2006; 36: 326-32.

6. Bozcali E, Dedeoglu DB, Karpuz V, Suzer O, Karpuz H. Cardioprotective effects of zofenopril, enalapril and valsartan against ischaemia/reperfusion injury as well as doxorubicin cardiotoxicity. Acta Cardiol 2012; 67: 87-96.

7. Nosálová V, Drábiková K, Jancinová V, et al. Protective effect of pheniramines against mesenteric ischaemia/ reperfusion-induced injury. Inflamm Res 2009; 58: 68-9.

8. Ulm AH, Miller F. An operation to produce experimental reversible hydronephrosis in dogs. J Urol 1962; 88: 337-41.

9. Josephson S, Robertson B, Claesson G, Wikstad I. Experimental obstructive hydronephrosis in newborn rats. I. Surgical technique and long-term morphologic effects. Invest Urol 1980; 17: 478-83.

10. Uyeturk U, Terzi EH, Kemahli E, Gucuk A, Tosun M, Cetinkaya A. Alleviation of kidney damage induced by unilateral ureter obstruction in rats by Rhodiola rosea. J Endourol 2013; 27: 1272-6.

11. Claesson G, Svensson L, Robertson B, Josephson S, Ceder lund T. Experimental obstructive hydronephrosis in newborn rats. A one-year follow-up study of renal function and morphology. J Urol 1989; 142: 1602-7.

12. Ozbek E, Ilbey YO, Ozbek M, Simsek A, Cekmen M, Somay A. Melatonin attenuates unilateral ureteral obstruction-induced renal injury by reducing oxidative stress, iNOS, MAPK, and NF-kappaB expression. J Endourol 2009; 23: 1165-73.

13. Erel O. A novel automated method to measure total antioxidant response against potent free radical reactions. Clin Biochem 2004; 37: 112-9.

14. Erel O. A new automated colorimetric method for measuring total oxidant status. Clin Biochem 2005; 38: 1103-11.

15. Toy H, Camuzcuoglu H, Celik H, Erel O, Aksoy N. Assessment of serum paraoxonase and arylesterase activities in early pregnancy failure. Swiss Med Wkly 2009; 139: 76-81.

16. Sancak EB, Tan YZ, Turkon H, Silan C. Attenuation of partial unilateral ureteral obstruction-induced renal damage with hyperbaric oxygen therapy in a rat model. Int Braz J Urol 2017; 43: 946-56.

17. Hosseinian S, Rad AK, Bideskan AE, et al. Thymoquinone ameliorates renal damage in unilateral ureteral obstruction in rats. Pharmacol Rep 2017; 69: 648-57.

18. Bayrak S, Yurekli I, Gokalp O, et al. Assessment of protective effects of methylprednisolone and pheniramine maleate on reperfusion injury in kidney after distant organ ischemia: a rat model. Ann Vasc Surg 2012; 26: 559-65.

19. Mak IT, Freedman AM, Dickens BF, Weglicki WB. Protective effects of sulfhydryl-containing angiotensin converting enzyme inhibitors against free radical injury in endothelial cells. Biochem Pharmacol 1990; 40: 2169-75.

20. Altunoluk B, Söylemez H, Bakan V, Ciralik H, Tolun Fl. Protective effects of zofenopril on testicular torsion and detorsion injury in rats. Urol J 2011; 8: 313-9.

21. Garrido V, Mendoza-Torres E, Riquelme JA, et al. Novel therapies targeting cardioprotection and regeneration. Curr Pharm Des 2017; 23: 2592-615.

22. Cacciatore F, Bruzzese G, Vitale DF, et al. Effects of ACE inhibition on circulating endothelial progenitor cells, vascular damage, and oxidative stress in hypertensive patients. Eur J Clin Pharmacol 2011; 67: 877-83.

23. Zhang $Y$, Rong $S$, Feng $Y$, et al. Simvastatin attenuates renal ischemia/reperfusion injury from oxidative stress via targeting Nrf2/HO-1 pathway. Exp Ther Med 2017; 14: 4460-6.
24. Gao D, Jing S, Zhang Q, Wu G. Pterostilbene protects against acute renal ischemia reperfusion injury and inhibits oxidative stress, inducible nitric oxide synthase expression and inflammation in rats via the Toll-like receptor 4/nuclear factor-кB signaling pathway. Exp Ther Med 2018; 15: 1029-35.

25. Ozkan TA, Karakoyunlu N, Polat R, et al. An evaluation of the protective effect of esomeprazole in an experimental model of renalischemia-reperfusion. Int Urol Nephrol 2018; 50: 217223. 